\title{
Aerobic exercise training and burnout: a pilot study with male participants suffering from burnout
}

Markus Gerber ${ }^{1 *}$, Serge Brand ${ }^{2}$, Catherine Elliot ${ }^{1}$, Edith Holsboer-Trachsler ${ }^{2}$, Uwe Pühse ${ }^{1}$ and Johannes Beck ${ }^{2}$

\begin{abstract}
Background: Occupational burnout is associated with severe negative health effects. While stress management programs proved to have a positive influence on the well-being of patients suffering from burnout, it remains unclear whether aerobic exercise alleviates burnout severity and other parameters related to occupational burnout. Therefore, the main purpose of this study was to pilot-test the potential outcomes of a 12-week exercise training to generate hypotheses for future larger scale studies.

Methods: The sample consisted of 12 male participants scoring high on the MBI emotional exhaustion and depersonalization subscales. The training program took place in a private fitness center with a $17.5 \mathrm{kcal} / \mathrm{kg}$ minimum requirement of weekly energy expenditure.

Results: The key findings are that increased exercise reduced overall perceived stress as well as symptoms of burnout and depression. The magnitude of the effects was large, revealing changes of substantial practical relevance. Additionally, profiles of mood states improved considerably after single exercise sessions with a marked shift towards an iceberg profile.

Conclusion: Among burnout patients, the findings provide preliminary evidence that exercise has the potential to reduce stress and prevent the development of a deeper depression. This has important health implications given that burnout is considered an antecedent of depressive disorders.
\end{abstract}

Trial registration: ClinicalTrials.gov Identifier: NCT01575743

Keywords: Aerobic exercise, Burnout, Depressive symptoms, Maslach Burnout Inventory, Mood, Stress

\section{Background}

The term burnout is used to describe a gradual depletion of energy combined with a loss of motivation and commitment after prolonged exposure to high occupational stress [1]. Examples of occupational stress include high workload, role conflicts, lack of participation or social support, injustice, uncertainty, under-reward, ambiguity, job insecurity, job complexity, as well as structural constraints [2-5].

Several validated instruments exist to assess burnout in working populations. Nevertheless, the most frequently used questionnaire is the MBI and its adaptations [1,6].

\footnotetext{
*Correspondence: markus.gerber@unibas.ch

${ }^{1}$ Institute of Exercise and Health Sciences, University of Basel, Basel, Switzerland

Full list of author information is available at the end of the article
}

Maslach and colleagues [7] operationalized burnout as a three-dimensional concept encompassing emotional exhaustion, depersonalization/cynicism, and reduced personal accomplishment. Emotional exhaustion describes feelings of depleted emotional resources, overstrain, tiredness, or fatigue and constitutes the individual energy component of the syndrome. Depersonalization/cynicism represents the interpersonal dimension of burnout which is characterized by negative, cynical, or excessively indifferent, distant and detached responses to other people at work and is associated with lack of work-related enthusiasm. Finally, reduced personal accomplishment contains a strong self-evaluative component and describes a drop in perceived competence, professional self-efficacy and productivity [7].

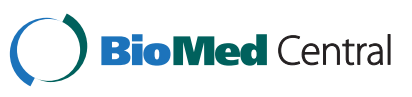


For several reasons, burnout presents an important public health problem and a cause of concern for policy makers [5]. Schaufeli and Enzmann [4] observed a considerable rise of stress-related compensation claims in various advanced economies. They further estimated that between $4 \%$ and $8 \%$ of the working population experience severe burnout. Ahola et al. [8] estimated the prevalence of mild and severe burnout in an epidemiologic study at $25 \%$ and $2.4 \%$, respectively. Furthermore, research has revealed a transfer of burnout symptoms from one employee to another [9]. Consequently, burnout may negatively impact the work atmosphere within a company or institution. Moreover, burnout has a high temporal stability. Across various occupational groups and cultural contexts, test-retest correlations varied between .50 and .60 even if participants were examined over several years $[10,11]$.

With respect to the consequences of occupational burnout, researchers found associations between high burnout and increased labour turnover and absenteeism rates [12], reduced organizational commitment [13] and lower job performance [14]. Additionally, previous investigations have shown that burnout negatively affects both aspects of mental and physical health. For instance, researchers have observed significant associations between burnout and increased depressive symptoms [15], as well as poor sleep and chronic fatigue syndrome [16-19]. Moreover, research has shown that burnout is linked with poorer self-rated health [20], and a variety of somatic complaints such as headaches and gastrointestinal problems [21]. Finally, both cross-sectional case-control studies and prospective investigations have shown that burnout is related to increased risk of cardiovascular disease related events with a relative risk comparable to other risk factors such as body mass index, smoking, blood pressure, and lipid levels [2].

In summary, the findings presented above indicate that the number of people unable to work due to mental difficulties has increased during recent decades and that burnout may be a vital component in this development. Consequently, knowledge about burnout prevention and efficient treatment are pivotal issues in the public health and economic perspectives. Previous intervention programs have focused on improving stress and emotion management techniques [4]. There are several legitimate reasons for stress intervention programs. First, chronic stress is a key factor in the causality of burnout. Second, negative coping strategies contribute to the maintenance and aggravation of burnout symptoms. Third, both stress and burnout have been linked with a dysregulation of the hypothalamic-pituitary-adrenocortical (HPA) axis [22].

The main purpose of the present study was to pilottest the potential of aerobic exercise training as a simple and inexpensive alternative stress treatment. So far, some studies have investigated the relationship between selfreported exercise and occupational burnout in general population samples [23-28], but no studies have been conducted that relate to whether a structured aerobic exercise training is able to reduce occupational burnout and associated symptoms of psychopathology among individuals with high initial burnout scores. Nevertheless, this is a pertinent issue because previous research has established links between high exercise and decreased levels of perceived stress [29-31]. Additionally, frequent exercise protects against impaired health if individuals are exposed to high stress demands [for review: 32]. Leisure time physical activity has been shown to buffer work-related stress [33,34], while randomized controlled trials have revealed that exercise interventions can reduce overall perceived stress [35]. Additionally, evidence exists that exercise has positive effects in the treatment of people suffering from depressive disorders [36-39]. Studies have also revealed that aerobic exercise training leads to enhanced mood [40]. Specifically, researchers observed that aerobic exercise results in mood states resembling an 'iceberg profile', which consists of elevated scores on the vigour subscale combined with low scores on depression, anger, confusion, fatigue and tension [41].

\section{Purpose}

The main purpose of the present pilot study was to explore whether a three-month aerobic exercise training program results in a) reduced levels of burnout, b) decreased depressive symptoms, and c) reduced stress perceptions. Furthermore, the present study aims to examine whether single exercise training sessions can improve mood, that is whether mood states will change in the direction of an 'iceberg' profile characterized by high vigour and low negative emotion states.

\section{Methods}

\section{Participants and procedures}

The sample consisted of twelve men $(M=45.8$ years, $\mathrm{SD}=$ 6.8; range 36-65 years) suffering from burnout syndrome based on Maslach's definition of occupational burnout [7]. All participants continued working during study participation. Participants were approached through different channels. Some participants were contacted via email because they completed a burnout questionnaire on a public website (www.swissburnout.ch), others received flyers from their general practitioners and psychiatrists, and some responded to public advertisements in hospitals, firms, offices and through publication in several discussion forums (e.g. http://forum.swissburnout.ch). All participants were screened via telephone interview prior to study enrolment by an experienced rater to ensure that all participants had high levels of work-related burnout. The following inclusion criteria were applied: a) high scores on the 
MBI subscales of 'emotional exhaustion' $(\geq 27)$ or 'depersonalization' ( $\geq 10$ ), male gender, aged between 30 to 65 years, non-smoking, good physical health, and not involved in regular exercise during the last two years. Subjects were excluded if they suffered from neurological illnesses, metabolic illnesses, liver or renal dysfunction, acute or chronic infectious diseases, neoplasias, or if they received pharmacotherapy or psychotherapy during the study.

\section{Study design}

This one-group pilot study was designed as a preexperimental, pretest-posttest investigation. All participants underwent a baseline examination one week before they started the 12-week exercise-training program. The examination used standard questionnaires to assess burnout severity, depressive symptoms and perceived stress. Baseline testing occurred under supervision of an experienced investigator who assisted the participants in the case of ambiguity. After baseline examination, all participants engaged in a 12-week exercise training at a private fitness centre under supervision of exercise coaches from the Institute of Exercise and Health Sciences at the University of Basel. Three days after successful completion of the exercise program, participants answered the same questionnaires under identical conditions. Additionally, six randomly selected participants answered a mood questionnaire on two occasions (week 5 and 9) immediately before and after the training session.

Prior to baseline testing, detailed information was given to all participants about the purpose of the study and the exercise program. Informed written consent was required and participants were aware that participation is voluntary and that they can discontinue participation at any time. The local ethics committee of Basel (EKBB) approved the study protocol and the investigation was conducted in accordance with the principles of the Declaration of Helsinki.

\section{Exercise training}

In accordance with the study by Dunn et al. [37], the aerobic exercise program was based on the exercise prescription guidelines of the American College of Sports Medicine [42]. The required level of weekly energy expenditure was $17.5 \mathrm{kcal} / \mathrm{kg}$. Energy expenditure was assessed using the values of burned calories provided by the training devices based on age, weight and training performance. Only the total weekly amount was used as a criterion. Accordingly, participants could choose their exercise frequency (between 2-3 trainings per week) and intensity. To allow for varied training and to avoid symptoms of physical overload, participants had a choice of different ergometers such as a cross trainer (Nautilus E916), a running ergometer (TechnoGym JogEcite), a stepping ergometer (TreadClimer ${ }^{\circledR}$ TC919), a bicycle ergometer (Life Fitness 95ci) and a rowing ergometer (Concept 2 Model E Indoor Rower P). Typically, participants exercised for about one hour, either two or three days per week. Participants were instructed to exercise within $60-75 \%$ of their maximum heart rate. The maximum heart rate was estimated according to the ACSM guidelines [42] using the formula: maximum heart rate = 220 - age (years) for untrained individuals. Heart rate was monitored during all training sessions with a chest belt heart rate monitor $\left(\right.$ Polar $^{\circledR}$ ) to ensure training below the anaerobic threshold. Training intensity was adjusted at baseline and after 6 weeks of training using the YMCAtest [43]. Participants were instructed to engage only in physical activity during the exercise intervention that they performed on a regular basis prior to the beginning of the program (e.g. cycling to work).

\section{Instruments}

Burnout symptoms: Work-related burnout was measured with a validated German version of the Maslach Burnout Inventory [1]. The MBI consisted of 22 items assessing the three sub-dimensions of emotional exhaustion (9 items; Cronbach's alpha $=.84$ [baseline] and .88 [follow-up]), depersonalization (5 items: Cronbach's alpha $=.89$ [baseline] and .76 [follow-up]) and personal accomplishment ( 8 items: Cronbach's alpha $=.89$ [baseline] and .88 [follow-up]). Responses were given on a 7 -point frequency rating scale, ranging between 0 (never) to 6 (every day). Burnout was represented by high scores on emotional exhaustion and depersonalization, and low scores on personal accomplishment. The three-factor structure of all versions of the MBI have been confirmed in several empirical studies across samples from different countries [44]. These investigations revealed that the three dimensions are conceptually distinct, but empirically related. Researchers have made recommendations against using an aggregate of the three MBI components [7].

Depressive symptoms: The Beck Depression Inventory [BDI: 45] was used to assess the severity of depressive symptoms. The BDI consists of 21 items including a range of affective, behavioral, cognitive, and somatic symptoms that are indicative of unipolar depression (e.g. 'I am so unhappy/sad that I can't stand it'). Participants were asked to select from four responses that reflect increasing levels of depressive symptomatology. Possible scores ranged from 0 to 63 with higher scores indicating more depressive symptoms. Adequate validity and reliability of the BDI have been shown previously [46]. The Cronbach's alpha in the present study was $\alpha=.85$ (baseline) and $\alpha=.87$ (follow-up).

Perceived stress: Overall perceived stress was assessed with the Perceived Stress Scale [PSS: 47], which is among the most widely used instruments for measuring 
perceived stress. The PSS consists of 10 items and draws on cognitive-transactional stress theory. Thus, the PSS measures the degree to which respondents find their lives unpredictable, uncontrollable, and overloading (e.g., 'How often have you felt that you could not control the important things in your life?'). Answers were given on a 5 -point Likert-scale anchored at 1 (never) to 5 (very often). Four items were reverse scored. Mean scores were calculated. Adequate validity and reliability of the PSS have been previously established [48]. The Cronbach's alpha in the present study was $\alpha=.71$ (baseline) and $\alpha=.86$ (follow-up).

Mood: Current mood states were assessed with a multidimensional instrument, the Befindlichkeitsskala [BFS: 49]. Prior research has indicated adequate validity and reliability of the BFS [49]. The BFS contains two bipolar core dimensions (high/low tension, negative/positive evaluation). The instrument consists of an adjective list for self-rating current psychophysiological mood states. The 40 items are answered on a Likert-scale ranging from 1 (not at all) to 5 (very much) and represent eight subscales with five items each. The dimensions are labelled as: anger (Cronbach's alpha $=.73-.87$ ), excitation (Cronbach's alpha $=.79-.90)$, activation (Cronbach's alpha $=.74-.95)$, elation (Cronbach's alpha $=.93-.95$ ), calmness (Cronbach's alpha = .90 - .91), contemplativeness (Cronbach's alpha $=.62$ - .64), fatigue (Cronbach's alpha =.62 - .80), depression (Cronbach's alpha = .93 - .94).

\section{Statistical analysis}

Changes in mean scores within the sample from pre to post exercise training were tested with paired-sample t-tests. All statistical calculations were performed with SPSS 18.0 for Apple Mac ${ }^{\circledR}$. Results with an alpha level below .05 were considered statistically significant. Given the small sample size involved in this pilot study, we also calculated effect sizes $(d)$ to interpret the meaningfulness of the data. Following Cohen's [50] recommendations, $0.20 \geq d \geq 0.49$ was considered to be small (e.g. negligible practical importance), $0.50 \geq d \geq 0.79$ was medium (e.g. moderate practical importance), and $d \geq 0.80$ was large (e.g. crucial practical importance).

\section{Results}

Participants significantly reduced their burnout symptoms after the 12-week aerobic exercise program. As presented in Table 1, participants reduced their feelings of emotional exhaustion, while concurrently experiencing less depersonalization. No significant changes were found with regard to personal accomplishment. Regarding the magnitude of the changes, large effect sizes were found for emotional exhaustion $(d=1.84)$ and depersonalization $(d=1.35)$. In turn, the scores for personal accomplishment pointed towards a change of negligible practical importance $(d=0.31)$. Figure $1 \mathrm{a}$ and $1 \mathrm{~b}$ show that ten of twelve participants reduced their emotional exhaustion and depersonalization scores, most of them to a considerable degree.

A significant reduction was also observed for depressive symptoms, with an effect size indicating a large change from baseline to follow-up $(d=1.54$; Table 1$)$. Figure $2 \mathrm{a}$ shows that all participants reduced their scores on the BDI over time.

Participants also significantly reduced their levels of perceived stress, with a large effect size for the intervention program $(d=1.76$; Table 1$)$. As Figure 2b shows, eleven of the twelve participants decreased their stress scores. Only one participant with a relatively low initial score maintained his level of previous stress.

In summary, our exploratory data suggest that a 12-week exercise program has the potential to reduce symptoms of occupational burnout, symptoms of depression and levels of perceived stress among male participants with high initial burnout scores.

The results regarding mood changes from before to after a single training session are summarized in Table 2 and 3. As illustrated in Figures $3 \mathrm{a}$ and 3b, participants' profiles of mood states clearly shifted towards an iceberg profile'. Although changes in most mood sub-dimensions were below the level of statistical significance, a closer inspection of effect sizes (between $d=|-0.60|$ and $|-2.00|$ ) revealed that the changes are indeed meaningful.

\section{Discussion}

The key findings of the present pilot study were that a 12-week aerobic exercise program successfully reduced

Table 1 Contrast of time 1 (Baseline) with time 2 (After 12 weeks exercise training) regarding psychopathological symptoms and stress

\begin{tabular}{|c|c|c|c|c|c|c|c|}
\hline & \multicolumn{2}{|c|}{ Time 1} & \multicolumn{2}{|c|}{ Time 2} & \multirow[b]{2}{*}{$t(11)$} & \multirow[b]{2}{*}{$p$} & \multirow[t]{2}{*}{ Cohen's $d$} \\
\hline & $M$ & $S D$ & $M$ & $S D$ & & & \\
\hline Emotional exhaustion & 40.18 & 6.15 & 26.75 & 8.29 & 4.75 & $<.001$ & 1.84 \\
\hline Depersonalization & 19.86 & 4.62 & 13.25 & 5.16 & 5.54 & $<.001$ & 1.35 \\
\hline Personal accomplishment & 30.47 & 7.47 & 34.50 & 5.49 & -1.64 & ns & 0.31 \\
\hline Depressive symptoms & 17.58 & 8.28 & 7.42 & 4.91 & 4.72 & $<.001$ & 1.54 \\
\hline Perceived stress & 26.50 & 3.78 & 17.92 & 5.95 & 4.50 & $<.001$ & 1.76 \\
\hline
\end{tabular}




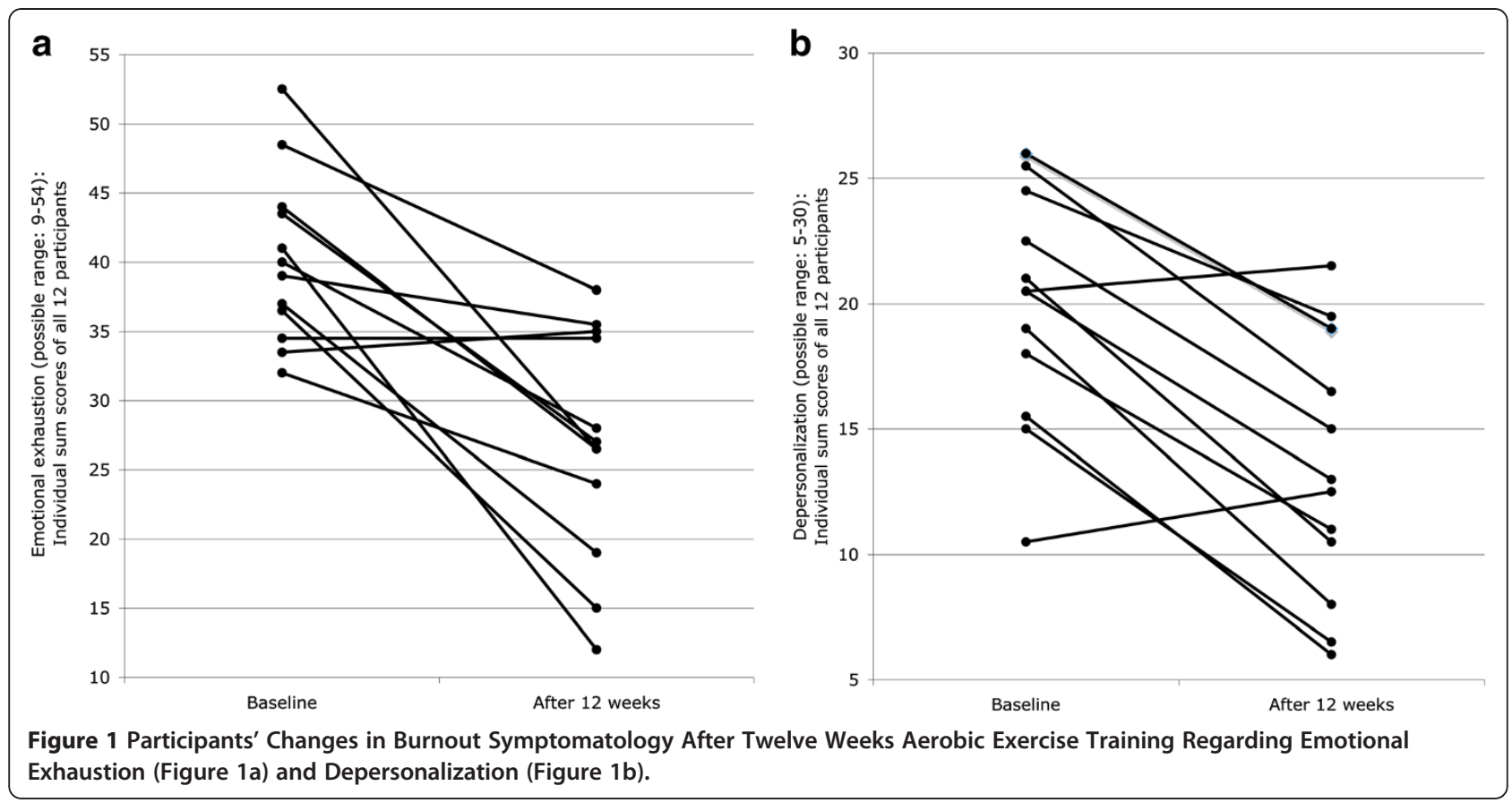

symptoms of burnout and depression in a sample of male participants scoring high on the MBI emotional exhaustion and depersonalization scales. Twelve weeks of exercise training also led to a significant reduction in perceived stress. All effect sizes were large, indicating changes of substantive significance. In addition, mood states improved considerably from before to after a single exercise session.

In a pilot-study with only 12 participants, our ambition was not to test hypotheses. Rather, this investigation was designed to generate empirical evidence, on which hypotheses can be based in future, large-scale studies. Furthermore, the effect sizes observed in this pilot study can be used to estimate the optimal sample size in forthcoming randomized controlled trials.

Melamed et al. [2] argued that the therapy of burnout is a challenging endeavour, as the success of many interventions may be limited by the fact that later stages of burnout entail physiological changes that are not easily reversed [16,51]. Previous research has shown that
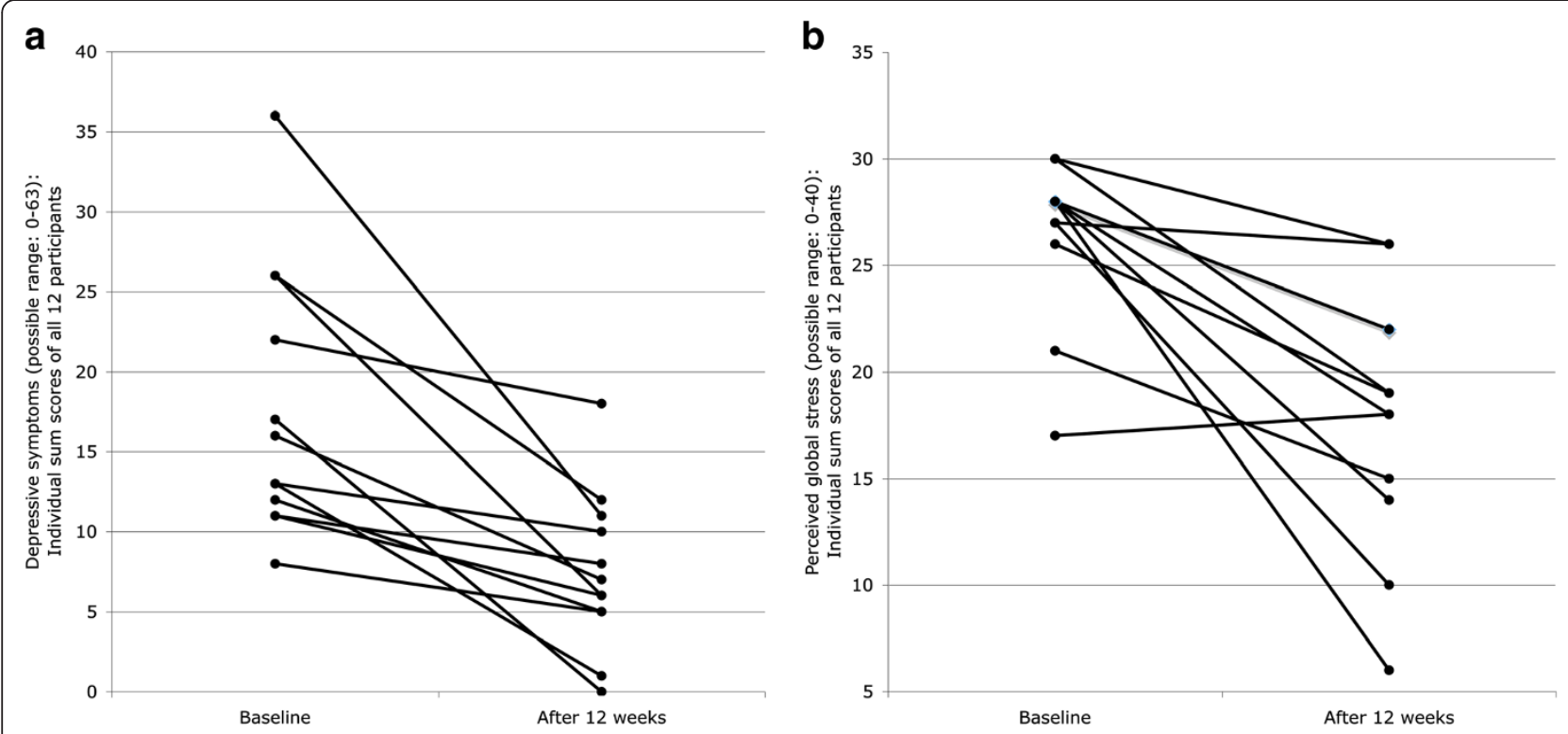

Figure 2 Participants' Changes in Depressive Symptoms (Figure 2a) and Perceived Global Stress (Figure 2b) After Twelve Weeks Aerobic Exercise Training. 
Table 2 Contrast of time 1 (Before training session) with time 2 (After training session) regarding mood states at week 5

\begin{tabular}{|c|c|c|c|c|c|c|c|}
\hline & \multicolumn{2}{|c|}{ Time 1} & \multicolumn{2}{|c|}{ Time 2} & \multirow[b]{2}{*}{$t(11)$} & \multirow[b]{2}{*}{$p$} & \multirow{2}{*}{$\begin{array}{c}\text { Cohen's } \\
d\end{array}$} \\
\hline & $M$ & $S D$ & $M$ & $S D$ & & & \\
\hline Anger & 1.52 & 1.05 & 1.00 & 0.00 & 1.10 & ns & 0.99 \\
\hline Excitation & 1.76 & 0.96 & 1.08 & 0.11 & 1.51 & ns & 1.27 \\
\hline Activatiion & 2.6 & 1.03 & 3.64 & 0.89 & -1.67 & ns & -1.80 \\
\hline Elation & 2.84 & 1.16 & 3.64 & 1.06 & -1.09 & ns & -0.72 \\
\hline Calmness & 2.68 & 1.25 & 3.36 & 1.03 & -0.85 & ns & -0.60 \\
\hline Contemplativeness & 2.08 & 0.72 & 1.6 & 0.55 & 1.11 & ns & 0.76 \\
\hline Fatigue & 1.84 & 0.84 & 1.12 & 0.27 & 1.88 & ns & 1.30 \\
\hline Depression & 1.52 & 0.64 & 1.12 & 0.18 & 1.45 & ns & 0.98 \\
\hline
\end{tabular}

aerobic exercise is negatively associated with symptoms of burnout [23-28], is suited to reduce perceived stress [29-31], and improves biological markers that may mediate between burnout and cardiovascular disease (i.e. sleep and immunology) [2]. Drawing on recent findings in depressive disorder research [36-39], positive effects of aerobic exercise training with burnout patients were hypothesized. Nonetheless, burnout and depression are separate, yet overlapping concepts. First, perceived fatigue and low levels of energy are a core component in all burnout measures and instruments to assess major depressive disorder [52]. Second, there are similarities between depersonalization, social withdrawal and learned helplessness, which are also involved in depression [46]. Conceptually, the two constructs are different in that depression is a global (context-free) affective state, whereas burnout is perceived in the work environment [9]. Accordingly, Schaufeli and Enzmann [4] showed that emotional exhaustion and depression shared only $26 \%$ of variance, while the degree of overlap was smaller for depersonalization (13\%) and personal accomplishment (9\%).

Table 3 Contrast of time 1 (Before training session) with time 2 (After training session) regarding mood states at week 9

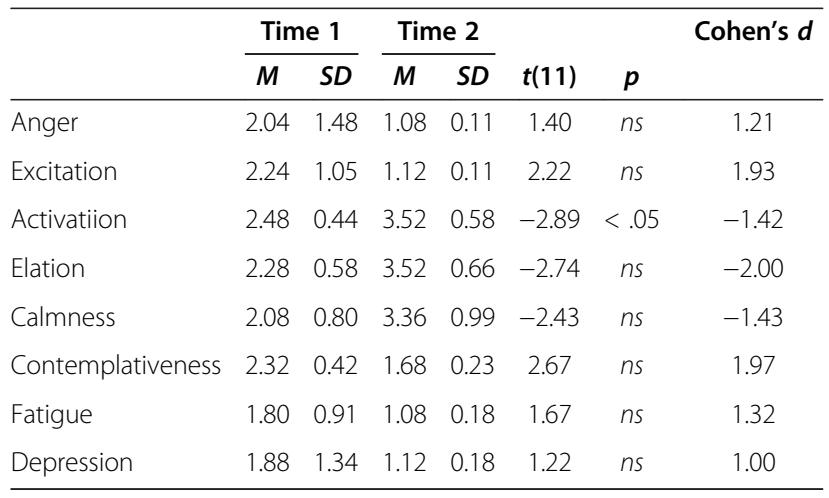

Since no prior research existed regarding the impact of aerobic exercise training among participants with high burnout scores, a pilot study seemed warranted. Despite the small sample size, our study provides promising and encouraging results in the sense that significant and clinically relevant changes were observed in almost all variables and in almost all participants. There were several reasons for these findings. First, participants might have perceived aerobic exercise as a burnout remedy. In particular, exercise is considered acceptable as a treatment against depression among adults, with a perceived effectiveness comparable to antidepressants and cognitivebehaviour therapy [53]. Second, aerobic exercise training might have contributed to improved sleep and recovery, which could have resulted in a decrease in emotional exhaustion [54]. Third, the close contact with the exercise trainers and the promotion of personal and social resources might have contributed to the reduction in depersonalization due to increased social support. Shirom et al. [5] argued that burnout is linked to a depletion of work-related resources, and that fostering resources that build up self-efficacy, hardiness and social support may provide positive results. We assume that aerobic exercise, as implemented in the present study, was well suited to improve these key resources. No improvements were found in the personal accomplishment subscale of the MBI. Exercise training did not directly influence the working-conditions of the participants. Therefore, it is possible for feelings of satisfaction to remain low in a climate of high job-pressures, low autonomy and lack of recognition.

It is also possible that re-occurring experiences of positive mood states may help to disrupt negative thinking cycles and thus prohibit the progression of cognitive downward spirals [55]. As noted by Terry [41], the "link between physical activity and mood is perhaps one of the most intuitively appealing relationships in the whole area of sport and exercise psychology. (...) However, intuitive appeal and empirical support is not the same thing" (p. 1). This study provides empirical support that moderate intensity exercise generally improves mood states of participants with high burnout scores.

One strength of the present study was the relatively homogeneous sample that diminished the influence of confounding factors. Additionally, participants were selected on the basis of high MBI scores and had not regularly exercised for at least twelve months prior to the exercise intervention. Another strength was that exercise training took place in a natural setting (private fitness centre with choice of ergometer) under controlled circumstances (supervised by experienced exercise trainers). This ensured that all participants fulfilled the a priori exercise requirements $(17.5 \mathrm{kcal} / \mathrm{kg}$ body weight per week, between $60-75 \%$ of maximal heart rate). Additional strengths were 

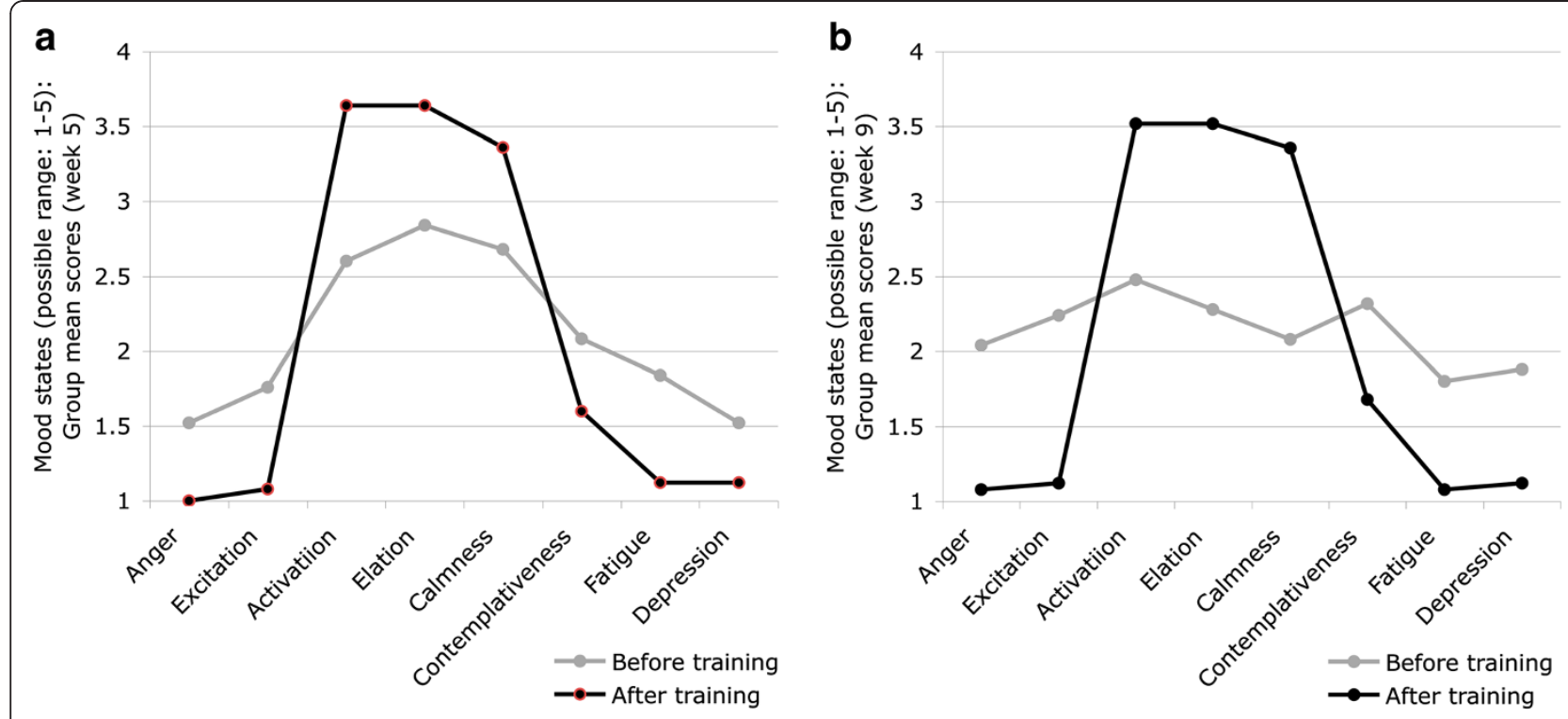

Figure 3 Changes in Mood States From Before to After a Single Exercise Session at Week 5 (Figure 3a) and Week 9 (Figure 3b).

that there was no participant mortality, that only validated measures were used to assess psychological variables, and that $p$-values, effect sizes, group means and individual scores were used to interpret the data.

Despite these strengths, some important limitations hindered the generalization of the findings. First, the study was designed as a one-group, pre-post-test investigation with no control group, placebo control group (e.g. performing table games) or waiting-list control group. With regard to internal validity, this design was relatively weak, only allowing observation of changes occurring within the intervention group. For instance, values might have changed naturally over time, or from events that took place during the treatment period. Since the intervention group started with relatively high levels of burnout, a regression to the mean seems plausible. Another important limitation was the small sample size. However, several depressive disorder studies [36-39] showed that it was apropos to assume a strong influence $(d \geq 0.80)$. Thus, with an alpha set at .05 and a power of .80 [47], twelve participants constituted a sufficiently large sample and allowed dependent $t$-test calculations. It remains uncertain whether exercise in a group setting would have resulted in different findings than a one-on-one supervision model. Also, the findings have limited generalizability since the sample included only non-smoking males with low levels of mental and physical co-morbidities who were not receiving pharmacotherapy or psychotherapy at the time of the study. Regarding the exercise program, limitations were that only prediction equations, although validated, were used to establish energy expenditure and maximum heart rate and that physical activity outside the gym was not systematically assessed.
Future studies should include a controlled design (e.g. randomized controlled trials with placebo treatments), using both genders and various populations (e.g. students). Furthermore, research should analyze different exercise types, individual and group settings, exercise combined with other forms of therapy, and the long-term effects of regular exercise. Above all, researchers should discover whether participants in structured programs could sustain regular exercise independently, and whether behavioural skill training (e.g., coping planning, facilitating social support) would prolong exercise maintenance.

\section{Conclusions}

The present pilot study delivered preliminary evidence that exercise reduces perceived stress among participants suffering from burnout, and prevents them from developing a deeper depression. This is important since burnout can be viewed as an antecedent of depressive disorders. Thus, exercise interventions might constitute a relatively simple and inexpensive alternative compared to pharmacotherapy or psychotherapy in the treatment of burnout, particularly as exercise does not only influence psychological well-being, but also impact physiological mechanisms that link burnout to cardiovascular disease and premature death.

\section{Competing interests}

All authors declare that they have no competing interests.

\section{Authors' contributions}

MG contributed to the conception and design of the study, the analysis and interpretation of the data and drafted the manuscript. SB, CE, EHT and UP were involved in the interpretation of the data and contributed to the revision of the drafted manuscript. SB provided knowledge regarding statistical and methodological problems. JB conceived the study, was 
responsible for data collection and co-authored the methods section of this manuscript. JB also provided knowledge regarding the interpretation of the data. All authors read and approved the final manuscript.

\section{Acknowledgements}

Funding for this study was provided by the Gottfried and Julia BangerterRhyner-Foundation (GJBRF), Basel, Switzerland. The GJBRF had no further role in the study design, data collection, data analysis, interpretation of data, writing of this manuscript, and in the decision to submit this paper for publication. All authors declare no conflicts of interests. The authors alone are responsible for the content and writing of the paper. We thank Ramona Amrein, Seraina Caviezel, Mirjam Lüthy, Tina Wunderlin, and Harald Kruse for their valuable contribution with regard to the implementation of the exercise training. We also thank Marielle König and Vladimir Djurdjevic for technical support. We further thank Daniel Gerber, the executive director of the Migros Fitnesspark Heuwaage, Basel, who allowed to implement the exercise intervention in his center. Finally, we thank all participants for their valuable time and effort to the study.

\section{Author details}

'Institute of Exercise and Health Sciences, University of Basel, Basel, Switzerland. ${ }^{2}$ Psychiatric Hospital of the University of Basel, Center for Affective, Stress and Sleep Disorders, Basel, Switzerland.

Received: 11 September 2012 Accepted: 26 February 2013 Published: 4 March 2013

\section{References}

1. Maslach C, Jackson S: The measurement of experienced burnout. J Occup Behav 1981, 2:99-113.

2. Melamed S, Shirom A, Toker S, Berliner S, Shapira I: Burnout and risk of cardiovascular disease: evidene, possible causal paths, and promising research directions. Psychol Bull 2006, 132:327-353.

3. Shirom A: Job-related burnout. In Handbook of occupational health psychology. Edited by Quick JC, Tetrick LE. Washington: American Psychological Association; 2003:245-265.

4. Schaufeli WB, Enzmann D: The burnout companion to study and practice: A critical analysis. Washington: Taylor \& Francis; 1998.

5. Shirom A, Melamed S, Toker S, Berliner S, Shapira I: Burnout and health review: current knowledge and future research directions. Int Rev Indust Organ Psychol 2006, 20:269-309.

6. Schaufeli WB, Leiter MP, Maslach C, Jackson SE: Maslach Burnout Inventory-General Survey. In The Maslach Burnout Inventory-Test Manual. 3rd edition. Edited by Maslach C, Jackson SE, Leiter MP. Palo Alto: Consulting Psychologists Press; 1996:19-26.

7. Maslach C, Schaufeli WB, Leiter MP: Job burnout. Annu Rev Psychol 2001, 52:397-422

8. Ahola K, Honkonen T, Isometsä E, Kalimo R, Nykyri E, Aromaa A, Lönnqvist J: The relationship between job-related burnout and depressive disorders results from the Finnish health 2000 study. J Affect Disord 2005, 88:55-62.

9. Bakker $A B$, Demerouti $E$, Schaufeli WB: The socially induced burnout model. In Advances in psychology research. Edited by Shohov SP. New York: Nova Science; 2003:13-30.

10. Bakker AB, Schaufeli WB, Sixma HJ, Bosveld W, Van Dierendonck D: Patient demands, lack of reciprocity, and burnout: a five-year longitudinal study among general practitioners. J Org Behav 2000, 21:425-441.

11. Toppinen-Tanner S, Kalimo R, Mutanen P: The process of burnout in white-collar and blue-collar jobs: Eight-year prospective study of exhaustion. J Organ Behav 2002, 23:555-570.

12. Parker PA, Kulik JA: Burnout, self- and supervisor-related job performance, and absenteeism among nurses. J Behav Med 1995, 18:581-599.

13. Lee RT, Ashforth BE: A meta-analytic examination of the correlates of the three-dimensions of job burnout. J App/ Psychol 1996, 81:123-133.

14. Cropanzano R, Rupp DE, Byrne ZS: The relationship of emotional exhaustion to work attitudes, job performance, and organizational citizenshop behaviors. J Appl Psychol 2003, 88:160-169.

15. Glass DC, McKnight JD: Perceived control, depressive symptomatology, and professional burnout: A review of the evidence. Psychol Health 1996, 11:23-48.

16. Grossi G, Perski A, Evengard B, Blomkvist V, Orth-Gomer K: Physiological correlates of burnout among women. J Psychosom Res 2003, 55:309-316.
17. Söderström M, Ekstedt M, Akerstedt T, Nilsson J, Axelsson J: Sleep and sleepiness in young individuals with high burnout scores. Sleep 2004 27:1369-1377.

18. Ekstedt M, Soderstrom M, Akerstedt T, Nilsson J, Sondergaard HP, Aleksander P: Disturbed sleep and fatigue in occupational burnout. Scand J Work Environ Health 2006, 32:121-131.

19. Brand S, Beck J, Hatzinger M, Harbaugh A, Ruch W, Holsboer-Trachsler E: Associations between satisfaction with life, burnout-related emotional and physical exhaustion, and sleep complaints. World J Biol Psychiatry 2010, 11:744-754.

20. Soderfeldt M, Soderfeldt B, Ohlson CG, Theorell T, Jones I: The impact of sense of coherence and high-demand/low-control job environment on self-reported health, burnout and psychophysiological stress indicators. Work and Stress 2000, 14:1-15.

21. Gorter RC, Eijkman MAJ, Hoogstraten J: Burnout and health among Dutch dentists. Eur J Oral Sci 2000, 108:261-267.

22. Moch SL, Panz VR, Joffe BI, Havlik I, Moch JD: Longitudinal changes in pituitary-adrenal hormones in South African women with burnout. Endocrine 2003, 21:267-272.

23. Ahola K, Pulkki-Raback L, Kouvonen A, Rossi H, Aromaa A, Lönnqvist J: Burnout and behavior-related health risk factors: results from the population-based Finnish health 2000 study. J Occup Environ Med 2012, 54:17-22.

24. Lindwall M, Ljung T, Hadzibajramovic E, Jonsdottir I: Self-reported physical activity and aerobic fitness are differently related to mental health. MENPA 2012, 5:28-34.

25. Jonsdottir I, Rödjer L, Hadzibajramovic E, Börjeson M, Ahlborg G: A prospective study of leisure-time physical activity and mental health in Swedish health care workers and social insurance officers. Prev Med 2010, 51:373-377.

26. Melamed S, Kushnir T, Shirom A: Burnout and risk factors for cardiovascular disease. Behav Med 1992, 18:53-60.

27. Melamed S, Shirom A, Toker S, Shapira I: Burnout and risk of type 2 diabetes: a prospective study of apparently healthy employed persons. Psychosom Med 2006, 68:863-869.

28. Toker S, Biron M: Job burnout and depression: unraveling their temporal relationship and considering the role of physical activity. J Appl Psychol 2012, 97:699-710.

29. Aldana SG, Sutton LD, Jacobson BH: Relationship between leisure time physical activity and perceived stress. Percep Mot Skills 1996, 82:315-321.

30. Schnohr P, Kristensen TS, Prescott E, Scharling H: Stress and life dissatisfaction are inversely associated with jogging and other types of physical activity in leisure time - the copenhagen city heart study. Scand J Med Sci Sports 2005, 15:107-112.

31. Wemme KM, Rosvall M: Work related and non-work related stress in relation to low leisure time physical activity in a Swedish population. J Epidem Commun Health 2005, 59:377-379.

32. Gerber M, Pühse U: Do exercise and fitness protect against stress-induced health complaints? A review of the literature. Scand J Public Health 2009, 37:801-819.

33. Gerber $M$, Kellmann M, Hartmann T, Pühse U: Do exercise and fitness buffer against stress among Swiss police and emergency response service officers? Psychol Sport Exerc 2010, 11:286-294.

34. Siu O, Cooper CL, Leung T: Three-wave trend study of managerial stress in hong kong: the role of type a behavior and exercise. Int J Stress Managem 2000, 7:153-157

35. Norvell N, Belles D: Psychological and physical benefits of circuit weight training in law enforcement personnel. J Consult Clin Psychol 1993, 61:520-527.

36. Blumenthal JA, Michael A, Babjak A: Exercise and pharmacotherapy in the treatment of major depressive disorder. Psychosom Med 2007, 69:587-596.

37. Dunn AL, Trivedi MH, Kampert JB, Clark CG, Chambliss HO: Exercise treatment for depression. Efficacy and dose response. Am J Prev Med 2005, 28:1-8.

38. Martinsen EW, Hoffart A, Solberg $\varnothing$ : Comparing aerobic and nonaerobic forms of exercise in the treatment of clinical depression: a randomized trial. Compr Psychiatry 1989, 30:324-31.

39. Mota-Pereira J, Silverio J, Carvalho S, Ribeiro JC, Fonte D, Ramos J: Moderate exercise improves depression parameters in treatmentresistant patients with major depressive disorder. J Psychiatr Res 2011, 45:1005-1011. 
40. Ekkekakis P, Acevedo EO: Affective responses to acute exercise: toward a psychobiological dose-response model. In Psychobiology of physical activity. Edited by Acevedo EO, Ekkekakis P. Champaign: Human Kinetics; 2006:91-110.

41. Terry PC: Introduction to the special issue: perspectives on mood in sport and exercise. J Appl Sport Psychol 2000, 12:1-4.

42. Pate RR, Pratt M, Blair SN, Haskell WL, Macera CA, Bouchard C, Buchner D, Ettinger W, Heath GW, King AC, Kriska A, Leon AS, Marcus BH, Morris J, Paffenbarger RS, Patrick K, Pollock ML, Rippe JM, Sallis J, Wilmore JH: Physical activity and public health. A recommendation from the Centers for Disease Control and Prevention and the American College of Sports Medicine. JAMA 1995, 273:402-407.

43. Golding LA: YMCA Fitness Testing and Assessment Manual. Champaign: Human Kinetics; 2000.

44. Schaufeli WB, Buunk BP: Burnout: An overview of 25 years of research and theorizing. In The handbook of work and health. Edited by Schabracq MJ, Winnubst JAM, Cooper CC. West Sussex: Wiley; 2003:383-42.

45. Beck AT, Ward CH, Mendelson M, Mock J, Erbaugh J: An inventory for measuring depression. Arch Gen Psychiatry 1961, 4:561-571.

46. Beck AT, Steer RA, Carbin MG: Psychometric properties of the beck depression inventory: twenty-five years of evaluation. Clin Psychol Rev 1988, 8:77-100.

47. Cohen $\mathrm{S}$, Kamarck T, Mermelstein R: A global measure of perceived stress. J Health Soc Behav 1983, 24:385-396.

48. Cohen S, Williamson GM: Perceived stress in a probability sample of the united states. In The social psychology of health. Edited by Spacapan S, Oskamp S. Sage: Newbury Park; 1988:31-67.

49. Abele A, Brehm W: Zur Konzeptualisierung und Messung von Befindlichkeit. Die Entwicklung der "Befindlichkeitsskalen" (BFS). Diagnostica 1986, 32:209-228

50. Cohen J: Statistical power analysis for the behavioral sciences. Mahwah: Erlbaum; 1988

51. Danhof-Pont MB, van Veen T, Zitman FG: Biomarkers in burnout: a systematic review. J Psychosom Res 2011, 70:505-524.

52. Suls J, Bunde J: Anger, anxiety, and depression as risk factors for cardiovascular disease: the problems and implications of overlapping affective dispositions. Psychol Bull 2005, 131:260-301.

53. Parker $\mathrm{G}$, Crawford J: Judged effectiveness of differing antidepressant strategies by those with clinical depression. Aust NZ J Psychiatry 2007, 41:32-37.

54. Brand S, Gerber M, Beck J, Hatzinger M, Pühse U, Holsboer-Trachsler E: Exercising, sleep-EEG patterns, and psychological functioning are related among adolescents. World I Biol Psychiatry 2010, 11:129-140.

55. Hobfoll SE: Stress, culture, and community. The psychology and philosophy of stress. New York: Plenum Press; 1998.

doi:10.1186/1756-0500-6-78

Cite this article as: Gerber et al:: Aerobic exercise training and burnout: a pilot study with male participants suffering from burnout. BMC Research Notes 2013 6:78

\section{Submit your next manuscript to BioMed Central and take full advantage of:}

- Convenient online submission

- Thorough peer review

- No space constraints or color figure charges

- Immediate publication on acceptance

- Inclusion in PubMed, CAS, Scopus and Google Scholar

- Research which is freely available for redistribution 